\title{
Post Walrasian Macroeconomics and IS/LM Analysis
}

\section{David Colander}

\section{Middlebury College}

In recent work I have tried to spell out a Post Walrasian approach to macroeconomics (Colander, 1995a) and to translate that Post Walrasian vision into the aggregate supply/aggregate demand framework (Colander, 1995b). In this paper I continue that work and begin to relate the Post Walrasian vision to the standard IS/LM analysis. The paper is not about high theory; instead it is about the pedagogical use of the IS/LM framework.

I undertake this exercise because, as James Tobin (1980) has noted, the IS/LM framework is built into the way economists think about the aggregate economy and macro policy. When they talk about expansionary fiscal policy, they picture in the back of their minds an IS curve shifting out; when they talk about contractionary monetary policy, they picture in the back of their heads an LM curve shifting back. These IS/LM stories might be modified by a variety of issues, but the influence of the IS/LM framework remains.

Although IS/LM analysis has been attacked vociferously by critics, advocates of its use are unrepentant. For example, Tobin, (1980), even while acknowledging the logical problems with IS/LM analysis, writes that "I do not think the apparatus is discredited. I still believe that carefully used and taught, it is a powerful instrument for understanding our economies and the impacts of policies upon them." Certainly, IS/LM's continued use suggests that Tobin's view is not unique to him. For example, Robert Solow (1984) concurs and offers an explanation of the phenomenon of IS/LM's use, despite concern about its logical foundations. He argues that IS/LM is useful in "training our intuition, to give us a handle on the facts." He says that the IS/LM model has survived because it proves to be a marvelously simple and useful way to recognize and process some of the main macroeconomic facts.

This paper starts from the premise that Solow and Tobin are essentially correctthat IS/LM analysis is useful and that it has survived because it does capture certain observed tendencies in the economy that economists should know, and that IS/LM analysis will continue to be used as a way of organizing economists' thinking about the macro economy.

The paper also starts from the premise that the critics are correct-that the current textbook foundations of IS/LM analysis are suspect; they are not the foundations that most economists would accept about the way the macro economy works and that, when carried to their logical conclusions, the standard static underpinnings of IS/LM analysis fall apart. 
What this paper is, then, is an attempt to rehabilitate IS/LM by giving it different underpinnings than the current texts give it. These Post Walrasian underpinnings lie in systemic institutional constraints that prevent competitive goods markets from adjusting prices instantaneously without undermining the structural integrity of those markets. Adding such structural constraints has not been part of the economists' formal approach, although it has often been part of their informal approach. Essentially what I am arguing is that the microfoundations lie in the formalization of traditional macro economists' informal approach. Until those microfoundations are formalized, my proposed solution is to be less formal in developing the microeconomic underpinnings of IS/LM models.

The ideas in this paper are not novel; as I stated above, this paper is a pedagogical, not a theoretical, paper. The ideas presented in it draw on, in varying degrees, the vision of traditional macro economists such as Tobin, Friedman, Keynes, Hayek, and Lerner. ${ }^{1}$ But, somehow, whenever their ideas were translated into a textbook IS/LM model, those ideas have been emasculated in an attempt to make them fit into a simple static explanation of the shapes of the IS and LM curves that are currently taught.

I begin the paper with a brief summary of the Post Walrasian vision; I then discuss how adopting that vision changes the way one thinks about modeling the aggregate economy, such as in how to interpret the short run and long run. Then I briefly discuss how that interpretation can change the pedagogical use of IS/LM analysis.

\section{The Post Walrasian Vision}

The Post Walrasian framework is based on a fundamentally different vision of the economy than is the Walrasian (interpret: multiple market economy in which equilibrium is assured by a Walrasian auctioneer) framework. The Post Walrasian vision is of a functionally complex economy, by which I mean an economy that is assumed to have complex dynamics and multiple equilibria that are related to those complex dynamics. One of the implications of this assumption is that a unique rational expectation for individuals cannot be derived since such derivation is beyond the modeling capabilities of individuals.

In a functionally complex economy extra-market coordination mechanisms are necessary; some unspecified "market" cannot be assumed to fully coordinate individuals' actions. How is this extra-market coordination accomplished? In the Post Walrasian vision that coordination is accomplished via institutions that place constraints on individuals that limit their range of choice, thereby reducing the set of achievable equilibria. Given institutions, there may be a unique equilibrium, but that equilibrium can only be understood in reference to the institutions that play a central role in determining it. In order to have a full analytic model within the Post Walrasian vision, one must (1) model the institutions within which individuals interact; (2) explain how those institutions are compatible with the assumptions of individual rationality that one has

\footnotetext{
${ }^{1}$ For a recent discussion of some of these ideas see Tobin (1994).
} 
made, and (3) explain how those institutions play a role in the determining the equilibrium of the economy.

Currently, economists are a long way form any such analytic model. This means that Post Walrasian IS/LM analysis cannot be a simplification of a more complex analytic model with firm microfoundations. At this point, the most we can claim for it is that it is a reduced-form description of institutionally-determined relationships without firm micro foundations. It is an empirically based, descriptive model, not a logically based, analytic model.

In formally modeling those institutions, and hence in modeling the economy, I have argued that a sequential modeling approach is necessary. All questions cannot be addressed simultaneously, and, at any moment in time, most individuals simply accept large numbers of institutions, and the constraints those institutions place on them, in order to reduce the complexity of decision making to a manageable level.

In the absence of sequentially determined decision making-and acceptance by individuals of social conventions and institutions - the complexity of interactions would lead one to expect that aggregate results would fluctuate wildly. That doesn't happen to anywhere near the degree that the complexity of the interactions would lead one to predict. Walrasians interpret that lack of fluctuation as an indication that their uniqueequilibrium approach is the correct one. Post Walrasians interpret that lack of fluctuations differently; they see it as an indication of the central role of institutions limiting the interactions in the economy to manageable proportions for individuals, and thereby creating a surface stability over a core of chaos.

Thus, the Post Walrasian view is that the economy processes information in a quite different way than is assumed in the Walrasian view. In Post Walrasian economics much of the information processing is built into existing institutions, and is not fully understood by the participants. Specialists may understand parts of it and they may be working on changing institutions to take advantage of that understanding, but the complexity of the economy precludes a full understanding of, and complete reliance on the results of, their analysis. Post Walrasian rationality has local, institutionally-based, characteristics; it is bounded, not global, rationality.

\section{Institutions as Operating Systems}

An analogy to a computer may shed some light on this Post Walrasian view of the role of institutions. A computer has a general design, an operating system, software built around that operating system, and sub-software built around that software. In using the computer most individuals take the existing software for granted, much as they take institutions for granted. They operate within the limitations of that software, and their rationality is defined by that software. Thus, when someone asks, "Why hit Control Z when the computer isn't responding?" one answers, "That's what one does.” Implicit in this response is the acceptance of a DOS environment. In a MAC environment hitting 
Control $\mathrm{Z}$ is meaningless. Other aspects of rationality carry over between two environments-double clicking with a mouse, for example, to open a file.

The same thing happens with institutions; individuals accept the constraints imposed by institutions on their actions as necessary constraints to operate in a complex environment. When asked why one drives on the right hand side of the street, one responds, “That's what one does." Similarly when asked why one displays the degree of honesty that one does, one does not respond, "I have analyzed the situation and determined that, given the costs and benefits, that is the optimal degree of honesty to reflect," as a Walrasian Homo Economus would. Instead, a Post Walrasian individual would state, "It's what is right." Now this doesn't mean that Post Walrasian Homo Economus is honest, or that he or she doesn't take costs and benefits of being honest into account. Instead it simply means that there is a large non-linear cost to determining optimal actions, and in many areas, the rational decision is to follow rules, learn what is, and is not, institutionally acceptable, and generally follow those institutional rules. ${ }^{2}$ Post Walrasians follow what Herbert Simon calls process rationality.

This sequential choice view of how the economy operates also dictates the modeling strategy used. To have a full model one must have a set of multiple nested systems - one explaining why institutions are adopted, and why sub-institutions are adopted. Most models will not concern such grand theories; instead they will accept existing institutions as given, and incorporate the constraints-like knowing about double clicking or Control Z - of those institutions into the analysis. One of the most important considerations for individuals will be limiting the nature of the decision they are making-efficiently reducing the amount of information processing they can do. Thus, the institutional constraints on micro behavior will be a central part of any but the grandest of models. They certainly play a central role in all short-run analysis; they place constraints on the type of behavior that can reasonably be assumed.

\section{The Post Walrasian Conception of Long Run and Short Run}

Adding a coordination role for institutions and a sequentially determined institutional structure has some important implications for the meaning we give to long run and short run. In Walrasian models, the difference between the long run and short run is simple: in the short run capital is fixed; in the long run capital is flexible. That distinction does not fit reality, since capital is often more easily changeable than is labor; hence the effect of the interpretation is that the applicability of results of the models to reality has been limited. Nonetheless, it has continued to be the key distinction between the long and short run. In the Post Walrasian construction, while there may be different degrees of lumpiness between labor and capital, that fixed/flexible capital difference is not the distinguishing feature between the long and short run. Indeed, in most of my initial thinking about the macro economy I find it useful to think of one composite input — an amalgam of capital and labor.

2 By including a psychic cost of being dishonest one can make the cost/benefit approach tautological, but that simply translates institutions into something that affects individuals' taste and hence part of the analysis since tastes can no longer be assumed exogenous. 
Instead, in the Post Walrasian model, the long run and short run distinctions center around what changes in coordinating institutions are allowed in the policy option you are considering. What is fixed is not capital; what is fixed is institutional environment-social conventions that determine the habitual ways of doing things. These habitual ways of doing things include pricing and inventory decisions and ways of approaching problems, as well as institutions such as corporate and market structure.

In the short run, the institutional environment is assumed fixed, and the primary macroeconomic coordination problems to be considered are expectational coordination problems that can occur within the existing institutional structure. For example, say everyone suddenly believes that aggregate demand is falling. That collectively-held expectation can cause suppliers to decrease production.

A specification of Post Walrasian short-run equilibrium involves specifying the way in which the economy coordinates expectations and how those expectations lead to an equilibrium in the economy within a range of possibilities set by existing institutions. Short-run analysis is the analysis of expectational coordination problems. Within the Post Walrasian view of macro, real fluctuations can be caused by changes in expectations as well as by real and nominal shocks. The short-run policy questions are: How well do existing institutions coordinate when presented with such shifts? And: What, if any, government actions can improve coordination?

The longer the run considered, the more institutions are allowed to change, and the greater the change in higher level coordination mechanisms. The penultimate long run is that time period in which all institutions are considered changeable. ${ }^{3}$ Thus, the long run and short run have nothing to do with an actual period of time, but instead have to do with the planning horizon individuals are using.

Which is the appropriate long run within which to model an economy? That is determined by the type of policy being analyzed, and the planning horizon that decision makers in the economy use. Returning to the computer analogy may shed some light on what I mean. Say one is initially operating in a DOS environment. One could, in a short time, change from a DOS environment to a Mac environment or a Windows 95 environment; at any point in time, varying numbers of individuals will be using different planning horizons and dealing with such changes. (Others may be thinking about even more substantial changes-for example, using DNA computing, which involves a totally different type of information processing than that used by existing computers. For them, the long run would include switching from the existing system to a DNA system. But, generally, when most individuals think about the long run, they will not be thinking about such a substantial change.) Those planning horizons used by individuals, not a set period of time, determine the long run one means in the model and determines the nature of changes in coordination that are analyzed. For example, corporations may or may not exist a century from now, but most of us will assume their existence in our planning horizon.

3 It should be quite clear that the penultimate long run is irrelevant to everyone in the economy except philosophers. 
When most macro economists talk about the long run they are not talking about the time it takes to change my broadly defined concept of institutions and conventions. They are instead assuming a fixed institutional structure-usually a perfectly competitive institutional structure-and talking about the time it takes to change the capital within that institutional structure. From a Post Walrasian perspective, this conception has two problems. First, the assumed perfectly competitive institutional structure is different than the existing institutional structure. That means that they are modeling a problem quite different from the problem that exists in our economy. From the Post Walrasian perspective, the degree of price and wage flexibility exhibited by the economy is intricately connected to existing institutional structure, and if you assume the existing institutions, you must also assume the existing degree of wage and price level flexibility.

In the Post Walrasian view the explanation of the degree of flexibility lies in the theory of institutions, not in the theory of economics, given institutions. It follows that any unemployment that results from a combination of fixed prices and wages cannot be assumed to be solvable by wage and price level flexibility. That solution would require a breakdown of existing institutions. In terms of IS/LM analysis it means that the IS curve is the end of the road that must, in its derivation, necessarily include some assumption about the allowable degree of price level flexibility. It is not a curve from which a new model consisting of two curves: one which is incorrectly called an AD curve (but which is actually a goods market equilibrium curve), the other an AS curve (labor market equilibrium) curve derived from the standard production function.

\section{The Importance of Institutions in Macro}

The computer analogy discussed above also sheds light on the multiple equilibria aspect of Post Walrasian macro, how it pictures institutions leading people to choose among those equilibria, and the approach to policy it suggests. In the grandest of models, there are many operating systems, and the choice of one of them will exclude others. Most policy issues are addressed-given an operating system, and hence it is difficult to base any statements about global optimality on economic models. One can make predictions about the effect of policies, given institutions, and the standard reactions of individuals given those institutions, but those predictions are more the equivalent of engineering predictions - rules of thumb - than they are scientific predictions about the way macro economies, in some abstract sense, work.

Seeing the institutional structure in this way has a direct impact on the way in which one structures the underlying IS/LM model. Specifically, one wants that model to be descriptive of real-world institutions, because it is those institutions that are the economy's operating system. Non-contextual deductive reasoning from individual rationality will not provide insight into how the real-world economy is likely to respond to shocks.

The systemic role of institutions is relevant for IS/LM analysis, and macro analysis generally, because it undermines the Walrasian approach to modeling. That approach involves assuming the price level is perfectly flexible, and the goods market is 
essentially an auction market. Our real world doesn't operate like that, and cannot operate like that. The degree of price level flexibility assumed by that approach (on the downward side) would undermine the structural integrity of the markets, causing the economy's operating system to crash. Thus, the degree of wage and price level flexibility assumed is not a modeling choice; it is a parameter that must be descriptive of the economy being described.

None of the above discussion would be novel to traditional macroeconomists, by which I mean old Keynesians or monetarists - that view of wage and price flexibility was part of their implicit understanding of the economy. But it was not part of the models, which were constructed within a Walrasian framework. Because it was not part of their formal model this traditional macro view was undermined as economists took seriously the challenge of developing a formal microfoundations.

The lack of any sense of this older view is obvious in New Classical work, but it is just as evident in much of the recent New Keynesian revolution. In this Post Walrasian view, the issue is not one of designing a model of imperfect competition that explains price and wage level inflexibility--the task New Keynesians have set for themselves. To even think in those terms presumes the meaningfulness of a "perfect competition" reference point. The Post Walrasian view is that without institutions there would be no economy as we know it; it is that market structure is part of the operating system of the economy, and that significant short-run price level flexibility is inconsistent with the functioning of markets as we know them. Perfect competition cannot serve as a benchmark by which to judge our economy. Instead, some concept of a "workably competitive" economy is the appropriate benchmark. (See Mark Blaug( ) for a discussion of the problems with a perfectly competitive benchmark.)

The New Classicals' and New Keynesians' failure to consider the role of institutions is the result of traditional macroeconomics' failure to specify the institutional limitations of macro models. It was that failure that, in many ways, led to the evolution away from traditional macro and towards New Classical macro. New Classical macroeconomics took seriously the global scientific claims of traditional macro. It then tried to rigorously set up the global foundations for macro in a perfectly competitive economy. It could not do so, so it claimed traditional macro was dead.

Once one takes a Post Walrasian view that individuals operate within constraints of an institutional structure (for which we have not yet developed a formal model) the New Classical claims disintegrate; there is no presumption that individual rationality leads to collective rationality. The goods market may be in long-run equilibrium, given institutions, at levels of output different than the economy’s potential output.

\section{Pedagogically Allowing for the Traditional Macroeconomics View}

As I stated above, this paper is about pedagogy, not about high theory, and the question I now turn to is how to incorporate this Post Walrasian view into the standard 
IS/LM model. My answer is: Be far humbler about what is being captured by IS/LM analysis than is currently the case.

Generally, IS/LM is presented in the texts with great fanfare as a simplified analysis formal model of the economy that has firm microeconomic foundations in an economy where the goods market is perfectly competitive. In the Post Walrasian institutional interpretation, IS/LM analysis isn't that, and should not be presented as that. Instead, it is a reasonable representation of the effects of shifts in the money supply, and of demand shocks in an economy with institutionally controlled prices, the analysis of the control of which we do not firmly understand. But that lack of understanding does not make the institutionally controlled prices any less real.

One way to make the limitations clearer is for economists, from the beginning, to emphasize the limited applicability of the IS/LM model. Currently, the IS/LM model is presented as a model based on a thought experiment that combines a predetermined combination of equilibrium interest rates and income levels in the money market with a predetermined combination of equilibrium interest rates and income levels in the goods market. The predetermination of these equilibria gives one an easy shorthand method of looking at the final equilibrium of many different policies. The analysis is standard, so I will not go through it here.

Such a thought experiment is far too grand for a Post Walrasian framework. In a Post Walrasian framework models of the aggregate economy have nowhere near the range of coverage that is generally claimed for the IS/LM model. Specifically, the assumptions that dynamics are complex - that the equilibrium is path dependent-makes it impossible to carry out the IS/LM thought experiment at the level of generality that is normally claimed for it. In a path dependent economy, predetermined equilibria do not exist independent of a starting point and the dynamic adjustment properties. Any system equilibrium is determined by the initial starting point and the dynamic path that the economy follows in response to a shift in one of the curves as it moves to a new equilibrium.

\section{A Model of First Order Changes}

To get around the problem, the Post Walrasian IS/LM approach uses a modified thought experiment that can be carried out under the assumption of path dependency. It is what might be called "a first order change" thought experiment. By this I mean the analysis takes as given that the starting point of the experiment is a long run equilibrium that has be arrived at through some historical process, and talks about changes from that equilibrium given the institutional assumptions that one is making.

This modified Post Walrasian thought experiment does not determine the full set of equilibria for the economy. It does not try to provide a complete model of the interest rate and income level in a timeless setting. In a path dependent system such a complete model would have to include all past history, since that history determines the current equilibrium. This thought experiment only provides a model of how the interest rate and 
income level will change from some starting point in response to shocks that hit the system. (Even this modified thought experiment requires the strong assumption that one begins the experiment in long-run equilibrium. In the real world one is never in long-run equilibrium. I justify such a starting point in two ways: First, it is the assumption used in the standard comparative static model; and second, as. a starting point in organizing one's thoughts about adjustment, it is a useful assumption.) While this limits the generality of IS/LM analysis, it is consistent with how the model is generally used-as a way to discuss the effect of a shift in monetary policy or fiscal policy. It provides an explanation of how monetary and fiscal policy can change potential income.

\section{A Modified Production Function}

To further emphasize the fact that IS/LM analysis does not have Walrasian microfoundation, one would also emphasize the complications that can arise in trading among individuals when there are not perfectly flexible prices, and the implications for aggregating into a composite production function that that presents. Currently this is not done. The basic framework of the formal models has not taken seriously the interdependence of supply and demand decisions that must be dealt with if one is to talk reasonably about an aggregate composite of goods in a market structure which is not perfectly coordinated by price.

The standard production function precludes doing so. In the standard production function either supply or demand takes precedent. This was inherent in the specification of the aggregate supply curve, which saw the aggregate production function as an individual production function, writ large. (In the traditional Keynesian presentation, demand creates its own supply; in the tradition Classical presentation, supply creates its own demand. In the Post Walrasian presentation, aggregate supply and demand are interdependent; one cannot analyze one without the other.)

What the standard specification of the production function rules out, by assumption, is any demand constraints being institutionally built into supply decisions. In the Keynesian interpretation of the standard model demand constraints and price inflexibility can lead to a demand-constrained economy, but there was always the implication that if only prices were flexible the economy could do better.

If one is to maintain a Post Walrasian vision, in which market structure is part of the operating system of the economy, one must directly deal with the problem of moving from an individual production function to an aggregate production function. The aggregate production function must include the possibility of strategic interdependence of the components of the aggregate; it must allow for the possibility that individual firms do not produce because they do not expect the demand for their product to exist.

To incorporate this inherent interdependence, I have argued that it is useful to think of the aggregate production function as differing from the individual firm production function by a coordination factor, C. This shift factor allows the amount producers choose to supply to the market to shift independently of changes in the level of 
employment, and hence independent of changes in the real wage. Even if both labor and capital were fixed in the relevant short run, output supplied could still fall if there is a fluctuation in expected demand because expectations of demand influence the coordination factor in the production function. (Notice that this specification allows for total labor productivity to fluctuate pro cyclically.)

At issue is how to interpret a demand-constrained aggregate equilibrium. In the standard production function, demand constrained equilibria are seen as representing disequilibrium points, off the desired supply curve. That is why it was seen as legitimate to add a supply curve, given by labor-market equilibrium curve, to the IS/LM-determined equilibrium points. In this standard interpretation the IS/LM equilibria were not true equilibria; they were goods market disequilibria. It is that characterization that Post Walrasians reject. What are ruled out by this view are any expectational problems or coordination failures on the part of the supply which are inherent to the structure of the economy. The "true" supply curve is given by the production possibility curve, which is essentially the economy's potential income determined solely by technical considerations. It allows for no coordination problems that make the economy's potential income lower than the technological limit of potential income. The only way that the true potential income could be reached was by having a perfectly flexible price level. That is not the case with a coordination augmented production function. In that production function demand-constrained equilibria can be full equilibria, given the assumed institutional structure.

Adding the coordination variable does not explain any of the above issues; such explanations involve complicated mathematics and are still the subject of research. The addition simply allows for such issues to be part of the story that accompanies the pedagogical model. It allows an expanded story accompanying the simple pedagogical model that we present to students.

Probably the most important of these implications in the interpretation of the IS/LM model is the implication that the same amount of capital and labor can be associated with different amounts of aggregate output, depending on the degree of coordination imposed by existing institutions. The short run production function is institutionally as well as technically determined. Thus, the Post Walrasian interpretation allows the analysis of aggregate production to go beyond the issue of relative prices. In doing this it changes the nature of policy discussion by allowing alternative paths for policy to influence the economy.

In my view a primary path through which policy is through its effects on expectations, and the coordination variable in the production function allows one to incorporate such effects in the interpretation of models. For example, fiscal policy or monetary policy might influence the coordination variable and thereby change the level of output, even if they do not affect a single relative price. The Post Walrasian foundations of IS/LM analysis will be on these extra-market coordination variables, and how monetary and fiscal policy can change coordination factors to bring about standard IS/LM policy conclusions. These changes make a substantial difference in the story we tell to explain the workings of the macro economy. 


\section{The Post Walrasian Explanation of the Impact of a Fall in Interest Rates on Investment}

The primary policy problem that monetary and fiscal policy might possibly solve in the Post Walrasian short run concerns coordination. Given a less than perfectly flexible wage and price operating system, expectations can become miscoordinated and expectations of low output can lead to low output. When people expect low demand, they produce low output, and their expectations are brought about by their own actions. Thus, there are a set of multiple equilibria that the economy can reach, any one of which could be an equilibrium depending on which expectations are chosen. The issue that IS/LM analysis needs to explain is how, and under what circumstances, does a fall in interest rates improve coordination, and hence lead to a downward sloping IS curve? With that downward sloping IS curve, an increase in the LM curve will lead the economy to a different equilibrium.

To see the argument of how this occurs, it is helpful to reconsider the disequilibrium saving/investment analysis above. Will a fall in the interest rate lead to a temporary increase in output or will savings be a binding constraint? In general, savings will not be the binding constraint. The reason is that there are two sources of savingsfrom existing income, and from wealth. Generally, savings from existing income is considered the only source of savings; savings coming from existing income can be a binding constraint. This follows since the source of this savings is prior to investment. However, savings can also come from someone guaranteeing a future payment from investment, say by establishing collateral based on their wealth. The people accepting this guarantee are saving, but it is not coming from prior income; it is coming from income that is being created by the investment. The investment increases income, and creates the actual savings necessary to finance it. Savings are simply financial assets that can be created whenever anyone is willing to accept a financial liability. So generally savings out of wealth can be created out of thin air simply by creating expectations of a growing economy. A fall in the interest rate, such as would be caused by expansionary monetary policy, is one way to get such savings created. This means that, except in times of financial crisis, investment, not savings, is the binding constraint, and there is an initial impact of a fall in the interest rate.

The Post Walrasian case assumes expectations can affect savings and that those expectations can drive the economy in the short run. Disequilibrium savings can be created out of thin air. When people believe the economy will do better, they are willing to make loans and accept more promises. If there were "too low" expectations before, this can improve the situation. Expectations of the state of the economy in the future, in conjunction with interest rates, are the driving force of savings. In normal times a fall in interest rates increases expectations of the future, so investment is the driving force when the savings market is in disequilibrium. A temporary fall in the interest rate brings about a rise in investment and output. That higher output creates patterns of trade coordination that did not exist previously, and in doing so, can increase the economy's potential income given the institutional structure. The savings curve shifts out and the economy arrives at a higher level of equilibrium. 
It is within this context that the historical debate about whether the interest rate is determined in the money market or goods market plays a central role. That debate has relevance to the Post Walrasian interpretation of IS/LM if it concerned disequilibrium interest rates. If the goods market interest rate predominated in disequilibrium, the temporary rise in investment accompanying a monetary-policy-induced fall in the interest rate would be short lived, and unlikely to generate any additional trade patterns and thereby increase the economy's potential income.

However, if the money market interest rate predominated, the goods market disequilibrium would be far more likely to affect real patterns of trade, creating new patterns and changing the long-run equilibrium interest rate and potential income of the economy. In this view, given the coordination mechanisms in the economy there is a range of interest rates and income levels that will represent possible equilibria for the economy. There is not a point, but, rather, a vector of possible outcomes, and which outcome the economy achieves depends on what monetary and fiscal policy the government chooses.

The Post Walrasian IS curve captures these outcomes. It is defined as the combination of potential equilibrium interest rates and income levels that can exist if the interest rate starts at interest rate $i^{*}$ and is raised or lowered by a given amount, assuming a given disequilibrium adjustment path. In the Post Walrasian framework potential income depends crucially on the degree of coordination in the economy. Other things constant, coordination is constant, but many things can affect it. Now say that, suddenly, real income expands above expected income-this expansion opens up new paths of coordination in the economy that otherwise were not possible, and with that increases potential income. The IS curve captures that increase in potential income that is brought about by a decrease in the interest rate in normal times.

In the complex-dynamics literature there are many ways in which the dynamics can affect the final equilibrium. The interpretation of IS/LM I proposed above assumes one of the simplest of these ways - that the dynamic path affects the final equilibrium in a continuous, deterministic way. Depending on whether the disequilibrium price is above or below the initial equilibrium price, and whether the disequilibrium quantities are above or below the initial equilibrium quantity, the equilibrium prices and quantities change in deterministic ways. This is an enormously strong assumption about the dynamic properties of the system. My two justifications for it are that (1) historically there is some empirical justification for this, and that empirical justification accounts for the longevity of IS/LM conclusions; and (2) the assumption, while enormously strong in reference to complex dynamics, is weaker than the standard assumption that no path dependency exists and that dynamics are not complex.

\section{Conclusion}

It is important to recognize what this Post Walrasian interpretation of IS/LM analysis is, and what it is not. It is not a general theory of aggregate income level in the economy, nor is it a theory of the interest rate. It is a component of both, but it is only a 
component. What the model says is that low income has a tendency to beget low income and high income has a tendency to beget high income. In some cases, by slightly pushing the economy with monetary and fiscal policy, we can increase its potential income by opening up individuals' eyes to trading possibilities that they did not previously recognize. This does not deny that the economy cannot be pushed too far, and can destroy existing patterns of coordination. IS/LM is not a general theory, but an organizing framework whose applicability to the real world depends $n$ institutional judgments about what is feasible.

Such a model is, I believe, useful to teach students. It eminently fits Tobin's and Solow's view of the usefulness of IS/LM as a thought-organizing tool, and it has the advantage of directing students' analysis into dynamics, rather than into the static nature of the curves. As opposed to making Keynesian analysis something that simply dismisses the New Classical challenge to wage/price flexibility, it answers it with a multiple equilibrium model in which the IS curve reflects assumptions of rational expectations, but not a unique equilibrium. Thus, within a Post Walrasian framework the Keynesian model is logical; whether it is something upon which policy can be based is a more difficult question that I will not address here. 


\section{Bibliography}

Blaug

Colander, David (ed.). 1996. Beyond Microfoundations: Post Walrasian Macroeconomics. New York: Cambridge University Press.

Colander, David. 1995. "The Stories We Tell: A Reconsideration of AS/AD Analysis.” Journal of Economic Perspectives.

Hicks, John (1980) “IS/LM: An Explanation” Journal of Post Keynesian Economics vol. 3 Winter

Nevile and Rao

Rao

Solow, Robert, (1984) "Mr. Hicks and the Classics," Oxford Economic Papers (vol. 36. Supplement)

Tobin 1994

Tobin, James. 1980. Asset Accumulation and Economic Activity . Oxford: Basil Blackwell.

Young, Warren, (1987) Interpreting Mr. Keynes Westview Press, Boulder, Colorado. 